\title{
Investigation of the renewed diseases on murals at Mogao Grottoes
}

\author{
Jiamin $\mathrm{Li}^{1}$, Hui Zhang ${ }^{1}$, Zaixuan Fan ${ }^{3,4}$, Xiang He${ }^{2}$, Shimin $\mathrm{He}^{1}$, Mingyuan Sun², Yimin $\mathrm{Ma}^{2}$, Shiqiang Fang ${ }^{2}$, \\ Huabing Zhang ${ }^{3,4}$ and Bingjian Zhang ${ }^{1,2^{*}}$
}

\begin{abstract}
In the past few decades, a series of research, restoration and protection have been performed on the ancient murals in Mogao Grottoes. These treatments played significant roles in the conservation of the elegant art in Dunhuang. But whether the protection and reinforcement are still active and which materials are more appropriate remain unknown. These issues are crucial for the conservation of murals. On-site investigation on the murals in Mogao Grottoes has been carried out. The purpose of this investigation is to examine the renewed diseases of the murals which have been repaired before. It will also provide useful information about the function of conservation materials and their degradation mechanism.
\end{abstract}

Keywords: Mogao Grottoes, Murals, Diseases, Conservation materials, Investigation

\section{Introduction}

Mogao Grottoes in Dunhuang, northwest of China (see Figure 1), are regarded as one of the most valuable cultural heritage sites in the world. Mogao Grottoes are famous for the murals, painted sculptures and wooden cave temple fronts. The Grottoes were initially excavated in $336 \mathrm{AD}$, and the excavation had been continued until Yuan Dynasty (1271-1368 AD). Now, there are 735 caves and about $45000 \mathrm{~m}^{2}$ murals existed. In 1987, the Grottoes were listed as the World Heritage Site by the United Nations Educational, Scientific and Cultural Organization (UNESCO) [1].

The murals in Mogao Grottoes are composed of plaster, white lime layer and pigment layer, which were painted on rock substrate. The rock substrate is conglomerate. Plaster is the mixture of clay, sand and jute (a plant fiber). Animal glue is believed to be the adhesion material. Several minerals, such as azurite $\left(2 \mathrm{CuCO}_{3} \cdot \mathrm{Cu}(\mathrm{OH})_{2}\right)$, minium $\left(\mathrm{Pb}_{3} \mathrm{O}_{4}\right)$ and malachite $\left(\mathrm{CuCO}_{3} \cdot \mathrm{Cu}(\mathrm{OH})_{2}\right)$, were used as the pigments. However, these murals have severely degraded due to natural and human factors over the long time. These factors not only affect the murals' artistic quality and integrity, but also threaten their safety [2].

\footnotetext{
* Correspondence: zhangbiji@zju.edu.cn

${ }^{1}$ Department of Cultural Heritage and Museology, Zhejiang University, Hangzhou 310028, China

${ }^{2}$ Department of Chemistry, Laboratory of Cultural Relics Conservation

Materials, Zhejiang University, Hangzhou 310027, China

Full list of author information is available at the end of the article
}

There are many typical diseases, including flaking, net cracks, disruption, detachment, paint loss and blister, as well as black smudges and graffito which were caused by human activities [3]. For example, black smoke was generated during the frequent Buddhist ritual activities in the caves with the use of candles and incense holders. These diseases can be divided into two categories: one was engendered in the past and has been relatively stable since then, such as sootiness, graffito and scratch. Another one can continually develop with the environmental change, and keep damaging the paintings, such as disruption and detachment. In Mogao Grottoes, there are more than 70 caves with this type of diseases $[4,5]$.

In order to preserve these valuable murals, the conservators of Dunhuang Academy have done lots of research, restoration and conservation in the past few decades. The environmental issue is critical to the deterioration of murals, therefore the monitoring of the micro-climate around the paintings can be effective for preventive protection [6-10]. Several reinforcement materials have been also used, which were selected based on tremendous fundamental research in the lab and practice in the field. However, some diseases occurred again a few years after conservation. The understanding of the current status of these protection and reinforcement materials has attracted much attention. Are the materials still active? Which treatments and materials are more appropriate? Do they have any long-term problems? How to solve the problems? These questions are critical for the future
() Chemistry Central

(c) 2013 Li et al.; licensee Chemistry Central Ltd. This is an Open Access article distributed under the terms of the Creative Commons Attribution License (http://creativecommons.org/licenses/by/2.0), which permits unrestricted use, distribution, and reproduction in any medium, provided the original work is properly cited. 


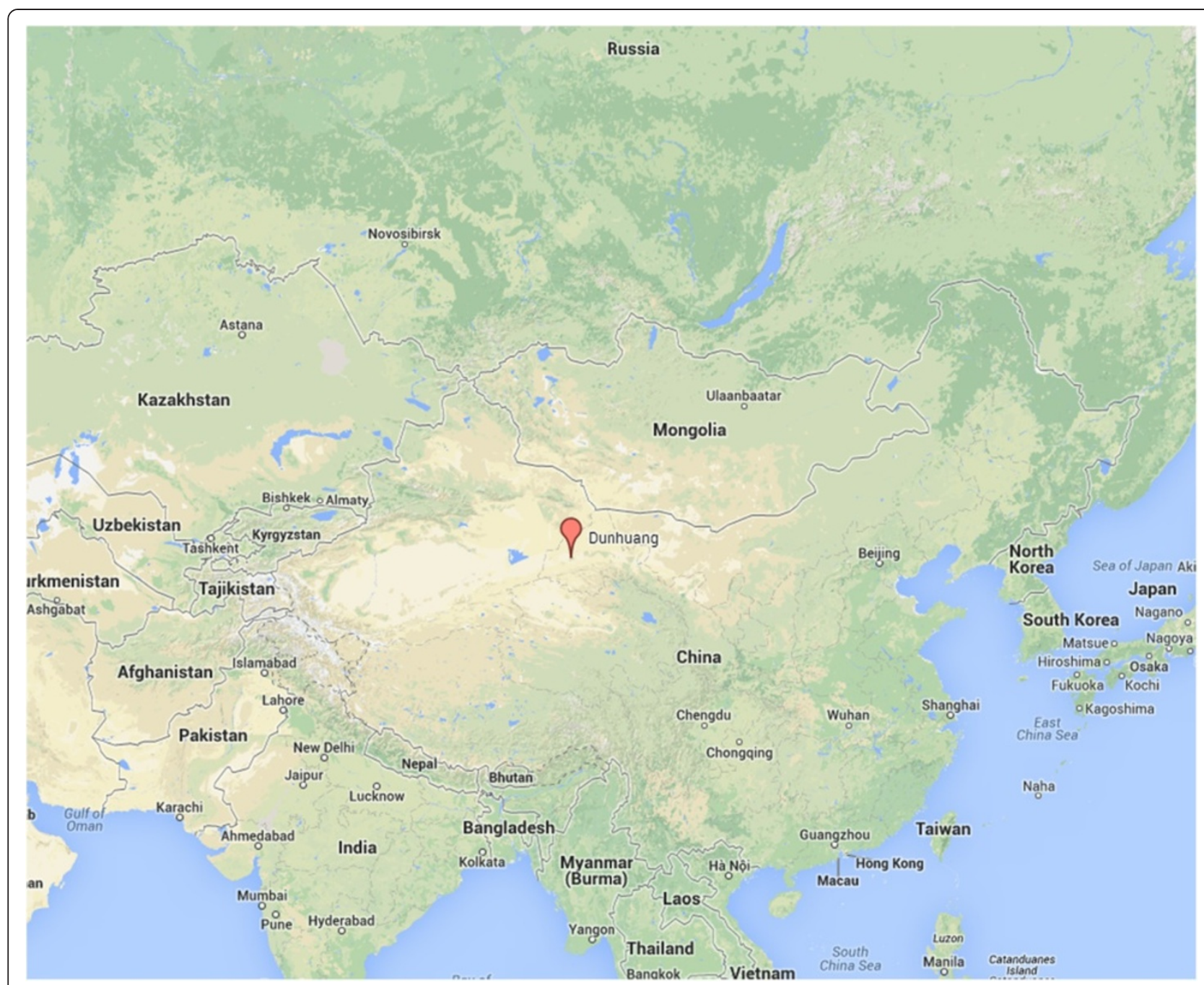

Figure 1 The location of Dunhuang.

protection of murals as well as the fundamental science behind.

In this work, on-site investigation in a few typical caves in Mogao Grottoes has been carried out. Different from the previous investigations in Mogao Grottoes [11-13], this investigation focused on the renewed diseases in the caves which have been repaired before. The purpose of the investigation is to summarize the successful experience in conservation work and find possible problems, such as the preservation damage caused by the conservation materials. The result of investigation not only helps to evaluate the conservation materials, but also offer help to understand their deterioration mechanism.

\section{Investigation}

\section{Restoration of mogao grottoes}

It is archaeologically revealed that repainting was the major way to conserve Dunhuang murals in the ancient time, which started since Sui and Tang Dynasties (581907 AD), and reached its peak in Song Dynasty (9601279 AD). Some murals of the Northern Dynasty (420-589 AD) were covered by those of Sui and Tang Dynasties, while some of Tang Dynasty covered by those of Five Dynasties (907-979 AD), Song Dynasty and Western Xia Dynasty (1038-1227 AD) [14]. For instance, people in late Tang Dynasty used to re-construct the murals of Northern Wei (386-534 AD) and early Tang Dynasties, leading to the art of multi-layered mural [15]. In general, it damaged the original murals; however, there are still a few covered murals in good condition after reconstruction, which means that repainting might be also protective.

The National Dunhuang Art Academy was established in 1944 and several conservation projects were carried out since then, such as removing sand in the caves and reinforcing the management of the grottoes. Due to the limits of human and financial resources, routine care 
was the leading conservation way at that time. In the recent 50 years, a series of salvage treatments, on both large and small scales, have been done to repair more than $3,000 \mathrm{~m}^{2}$ murals with diseases like detachment, flaking, and disruption [16,17].

Salvage treatments include: reattaching the flaking murals, reinforcing the disruption and the paint layers' cracks, grouting the detachment parts, and so forth. Materials for reattachment and reinforcement [18] are critical to the conservation. A series of screening studies and experiments [17-19] have been performed through long-term conservation practice, and three types of materials were mainly used: polyvinyl acetate emulsion (PVA), which has been put into use since the 1950s to 1960s in the 94th and 108th caves [20-23]; the hybrid acrylic and silicone acrylic emulsion, which has been applied for flaking over ten years in the 23th and 217th caves; the last one is gelatin solution. Since the original binding materials of murals are the natural water-soluble materials like oxhide gelinsidein, gelatin solution has been used in the repair work in the 85th and 98th caves [24,25].

\section{Investigation methods and results}

Several caves in Mogao Grottoes which had been repaired by PVA, the hybrid emulsion of acrylic and silicone acrylic (the hybrid emulsion), or gelatin solution were investigated. These materials have been chosen based on lots of scientific experiment and field applications by Dunhuang Academy. In order for easy comparison, all the investigated caves are located in the bottom level of Mogao Grottoes. The whole investigation was performed based on the requirements described in the National Standards of Specification for Condition Survey of Ancient Murals [26].

During the investigation, the disease area was measured using rulers (see Figure 2). Keyence VHX-2000 microscope (Dino-Lite AD413T) was used to observe the salt aggregation on the surface of the murals. Infrared thermography (NEC G100) was applied to identify the detachment of murals.

The diseases which were investigated include flaking, paint loss, deep loss, disruption, detachment, net cracks and punctate loss. These diseases can be divided into slight, mild and severe levels according to the damage degree. In this survey, the total area of the repaired murals is $411.38 \mathrm{~m}^{2}$ (the survey area). The area of the murals repaired by PVA is $138.72 \mathrm{~m}^{2}$, the area of the murals repaired by the hybrid emulsion is $116.89 \mathrm{~m}^{2}$, and the area of the murals repaired by gelatin solution is $155.77 \mathrm{~m}^{2}$. The total area of the repaired murals with the renewed diseases is $41.54 \mathrm{~m}^{2}$ (the disease area). The detail of the survey results is shown in Table 1 . The survey result indicates that the renewed diseases at Mogao

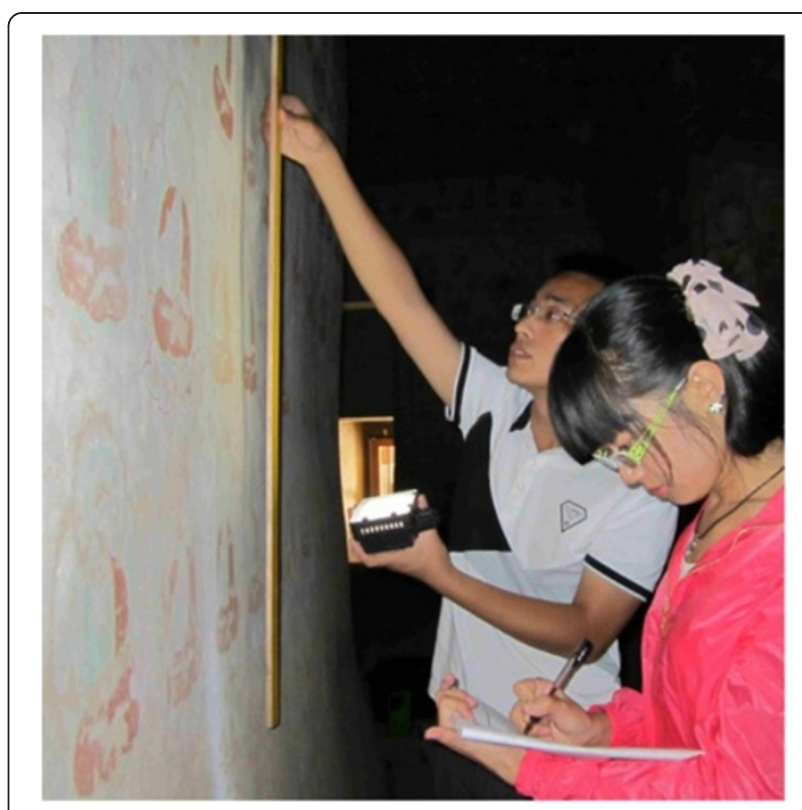

Figure 2 On-site Investigation of the renewed diseases of the repaired murals.

Grottoes mainly include disruption, flaking, detachment and paint loss (Figure 3).

Table 1 shows that the most hazardous deterioration on the murals repaired by PVA contains disruption, detachment and paint loss. The most hazardous deterioration on the murals repaired by the hybrid emulsion contains disruption, flaking and paint loss. The most hazardous deterioration on the murals repaired by gelatin solution contains disruption, flaking and detachment.

In this survey, most of the renewed diseases were distributed in the region up to $2 \mathrm{~m}$ above the ground. The region between $0.5-2 \mathrm{~m}$ above the ground is about $98.3 \%$ in the disease area. Most of the regions below $0.5 \mathrm{~m}$ have been repaired because of severe damage in the past. There are only a few paintings left in this region, so the renewed diseases account for only $1.2 \%$ of the diseases area. In addition, the disease in the region over $2 \mathrm{~m}$ above the ground account for only $0.5 \%$ of the diseases area. The upper region in the caves has almost no significant diseases, and the proportion of the renewed diseases is the least in that region.

The diseases of murals in different caves are quite different even using the same conservation material to repair the murals. It is obviously that the renewed diseases are closely related to the caves' location and their surrounding environment.

\section{Diseases distribution and their causes}

All the caves in this investigation are located in the bottom grottoes. Compared to the upper caves, more severe diseases occurred in the bottom. There is no doubt that 
Table 1 The area of renewed diseases on murals repaired by different conservation materials

\begin{tabular}{|c|c|c|c|c|c|c|c|c|c|}
\hline \multirow{2}{*}{$\begin{array}{l}\text { Conservation Materials } \\
\text { Diseases }\end{array}$} & \multicolumn{2}{|l|}{ PVA } & \multicolumn{2}{|c|}{ the hybrid emulsion } & \multicolumn{2}{|c|}{ gelatin solution } & \multirow{2}{*}{$\begin{array}{l}\text { Total } \\
\text { Area } \\
\left(\mathrm{m}^{2}\right)\end{array}$} & \multirow{2}{*}{$\begin{array}{l}\text { Disease } \\
\text { Area } \\
\text { Proportion } \\
\text { (\%) }\end{array}$} & \multirow{2}{*}{$\begin{array}{l}\text { Survey } \\
\text { Area } \\
\text { Proportion } \\
\text { (\%) }\end{array}$} \\
\hline & $\begin{array}{l}\text { Area } \\
\left(\mathrm{m}^{2}\right)\end{array}$ & $\begin{array}{l}\text { Proportion } \\
\text { (\%) }\end{array}$ & $\begin{array}{l}\text { Area } \\
\left(m^{2}\right)\end{array}$ & $\begin{array}{l}\text { Proportion } \\
\text { (\%) }\end{array}$ & $\begin{array}{l}\text { Area } \\
\left(\mathrm{m}^{2}\right)\end{array}$ & $\begin{array}{l}\text { Proportion } \\
\text { (\%) }\end{array}$ & & & \\
\hline Disruption & 7.57 & 51.43 & 6.79 & 33.85 & 2.02 & 29.88 & 16.38 & 39.4 & 3.98 \\
\hline Flaking & 0.63 & 4.28 & 6.25 & 31.16 & 2.21 & 32.69 & 9.09 & 21.9 & 2.21 \\
\hline Detachment & 3.95 & 26.83 & 0.07 & 0.35 & 2.53 & 37.43 & 6.55 & 15.8 & 1.59 \\
\hline Paint Loss & 2.16 & 14.67 & 4.27 & 21.29 & 0.00 & 0.00 & 6.43 & 15.5 & 1.56 \\
\hline Net Cracks & 0.07 & 0.48 & 2.13 & 10.62 & 0.00 & 0.00 & 2.20 & 5.3 & 0.53 \\
\hline Deep Loss & 0.34 & 2.31 & 0.41 & 2.04 & 0.00 & 0.00 & 0.75 & 1.8 & 0.18 \\
\hline Punctate Loss & 0.00 & 0.00 & 0.14 & 0.70 & 0.00 & 0.00 & 0.14 & 0.3 & 0.03 \\
\hline Total Area $\left(\mathrm{m}^{2}\right)$ & 14.72 & & 20.06 & & 6.76 & & 41.54 & & \\
\hline Disease Area Proportion (\%) & 35.44 & & 48.29 & & 16.27 & & & & \\
\hline Survey Area Proportion (\%) & 3.58 & & 4.88 & & 1.64 & & & & \\
\hline
\end{tabular}

these diseases are closely related to the moisture environment in the caves. The moisture in bottom rocks (including groundwater, surface water and condensed water) is greater than the upper. Moreover, water from the Daquan River in front of Mogao Grottoes entered the bottom caves in flood season [27], so seasonal damp is the important reason for the diseases. In addition, soluble salts play significant role. One survey showed [28] that the salt content in bottom caves is the highest, and it is gradually decreasing with the height. The soluble salt ions mainly include $\mathrm{Na}^{+}, \mathrm{K}^{+}$, $\mathrm{Mg}^{2+}, \mathrm{Cl}^{-}$and $\mathrm{SO}_{4}^{2-}$, which do great harm to the murals [29-31]. It is not only one of the reasons why almost all murals near the ground are missing in the bottom caves, but also the main cause of diseases appearing again after repair.

\section{Disruption}

Disruption refers to the mural plaster being loose and damaged as a result of the actions of soluble salts. According to our survey, the proportion of disruption, with an area of $16.37 \mathrm{~m}^{2}$ in total, is the highest in all the diseases (reaching up to 39.4\%) (Table 2). Almost all of the investigated caves are threatened by disruption. Therefore, disruption is one of the most severe diseases at Mogao Grottoes which greatly affects the murals.

Previous research proved that mural damages result from the subflorescence of soluble salts with water infiltration and migration. Water can move through the plaster, and then evaporate from the surface. The changes of relative humidity in the grottoes will make soluble salts repeatedly dissolve and crystallize, while the plaster repeatedly expand and shrink. Then the plaster

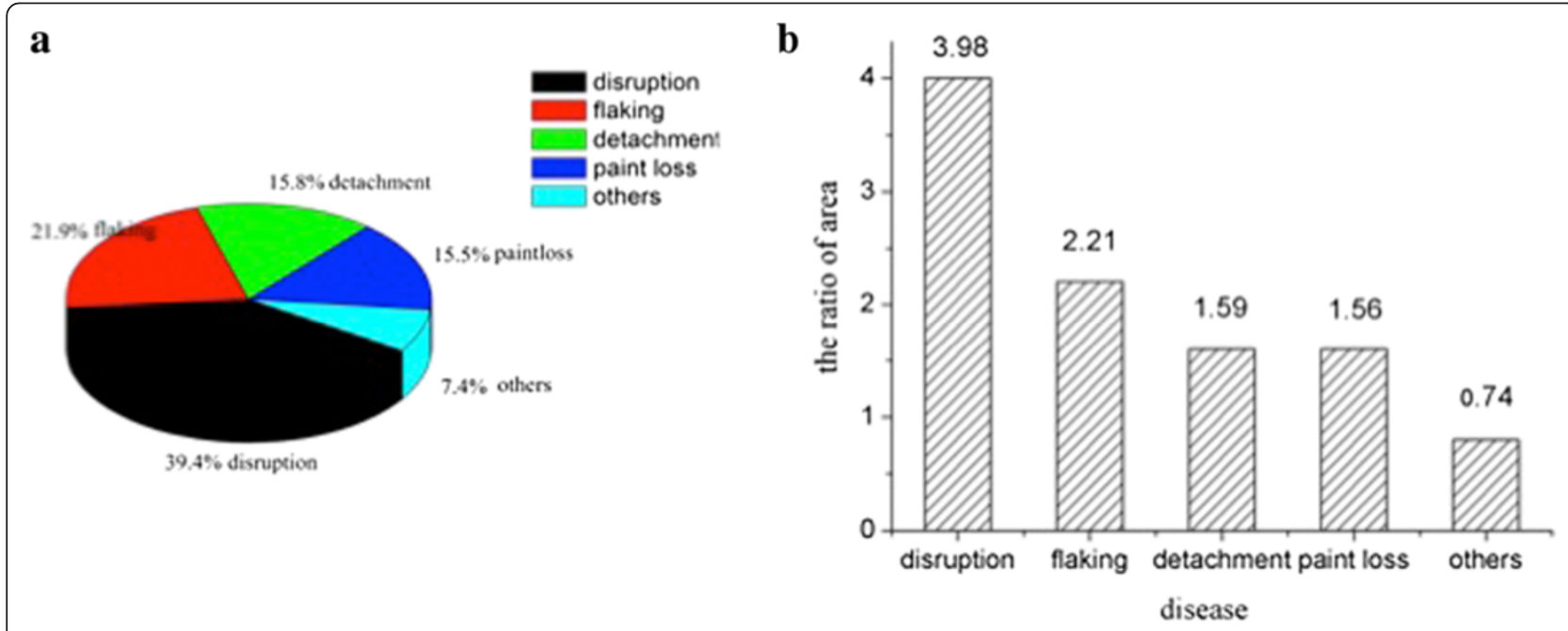

Figure 3 Proportion of the renewed diseases. (a) the proportion of the renewed diseases in the disease area; (b) the proportion of the renewed diseases in the survey area 
Table 2 The degrees of renewed diseases at Mogao Grottoes

\begin{tabular}{|c|c|c|c|c|c|c|c|c|}
\hline \multirow[b]{2}{*}{ Degree } & \multicolumn{2}{|l|}{ Disruption } & \multicolumn{2}{|l|}{ Flaking } & \multicolumn{2}{|c|}{ Detachment } & \multicolumn{2}{|l|}{ Paint Loss } \\
\hline & Area $\left(m^{2}\right)$ & Proportion (\%) & Area $\left(\mathrm{m}^{2}\right)$ & Proportion (\%) & Area $\left(m^{2}\right)$ & Proportion (\%) & Area $\left(m^{2}\right)$ & Proportion (\%) \\
\hline severe damage & 12.3 & 75.09 & 5.40 & 59.40 & 5.07 & 77.40 & 3.98 & 61.90 \\
\hline moderate & 3.11 & 18.99 & 1.84 & 20.24 & 1.15 & 17.56 & 1.90 & 29.55 \\
\hline slight damage & 0.97 & 5.92 & 1.85 & 20.35 & 0.33 & 5.04 & 0.55 & 8.55 \\
\hline total & 16.38 & & 9.09 & & 6.55 & & 6.43 & \\
\hline
\end{tabular}

of mural becomes loose during this process. Disruption is characterized by the crumbling of soil and paint layer. Therefore, the formation of disruption is mainly influenced by the following factors. First, soluble salts in the mural plaster and rock are the basic material resources to cause disruption. Second, the alterations of temperature and humidity in the caves drive the water migration. Finally, the cycles of salt solvation - crystallization with water directly lead to disruption.

Reinforcement and desalination have been used to fix disruption at Mogao Grottoes. PVA has been mainly used to repair the disrupted murals in the early time. In recent years, gelatin solution has been more frequently used as the reinforcement material. In desalination, a series of materials and techniques were used to remove the salts accumulated in the plaster layer [32]. It was found that desalination played an important role to prevent the diseases appearing again. The area of renewed diseases on murals treated by desalination was $50 \%$ less than the area of murals without desalination. In this investigation, it was found that disruption usually became more severe in the regions where disruption had never been repaired. The content of soluble salts in these regions was still higher than elsewhere. It suggests that the renewed disruption disease is closely related to soluble salts. However, it is difficult to completely remove the salts in the murals, because soluble salts in the surrounding rock can continuously migrate to the plaster layer.

The most severe disruption disease in one investigated cave is on its west wall and the other two walls close to the west wall, but disruption on its east wall is slight. The major soluble salts causing the mural disruption in Mogao Grottoes are $\mathrm{Na}_{2} \mathrm{SO}_{4}$ and $\mathrm{NaCl}$ from the plaster layer and rock [33-36]. The analysis of soluble salts in this cave shows that the plaster layer contains $\mathrm{Cl}^{-}, \mathrm{Na}^{+}$ and $\mathrm{SO}_{4}^{2-}$, which are mainly distributed in the west wall and nearby. The salts analysis of the rock body also indicates that the content of soluble salts in the west wall is $2 \sim 3$ times higher than the east wall, because the salt distribution is affected by the depth of the cliff [4]. The renewed disruption on the west wall is severe. A large amount of soluble salt crystallization can be seen on the disruption with the help of microscope (Figure 4).

Based on the above analysis, it can be concluded that the effective measures to control disruption should be as follows. First, effective treatments should be taken to remove soluble salts in the plaster layer and rock body. Second, efficient environment control should be applied to maintain the caves in a relatively stable condition and reduce the migration of water and soluble salts. In order to avoid direct sunlight and sand erosion, the conservators controlled the environment by installing doors for the caves about 50 years ago. Then, they used sensor devices to monitor carbon dioxide levels. When the content of carbon dioxide exceeds the standard, they will evacuate the caves and keep the caves close for several days. Now, they gradually began to control temperature and humidity. Finally, if the severe disruption has to be repaired, the conservation materials with good water vapor permeability should be used.

\section{Flaking}

Flaking refers to the cracks of grounding layer or the paint layer and the resulting warped fragments. Flaking is an early stage of peeling, exfoliation, delamination or spalling, and can be seen as the detachment of small, flat, thin pieces of the paint layer from the mural. Our investigation results show that the area with flaking is about $9.08 \mathrm{~m}^{2}$, accounting for $21.9 \%$ of the total disease areas, $59.4 \%$ of which is severe.

There are two common reasons for flaking. One is the deterioration of the original adhesion material in the murals; the other is the reinforcement material used to repair the murals.

Flaking due to the deterioration of the original adhesion material can be recognized as the separation of the grounding layer or the paint layer from the plaster or lamellar cracking. The reason is that the cohesive decreases with the deterioration of the adhesion material, making the grounding layer or the paint layer separate from the plaster. Especially the murals with dense plaster layer and smooth surface are easy to crack and warp when the adhesive material deteriorates because of the obviously different properties between layers. Flaking usually appeared in the region with thicker paint layer and higher content of adhesive material [23]. Flaking caused by this reason mostly belongs to mild or slight disease. For instance, slight flaking due to thick paint layer can be recognized on the center column in the 44th cave (Figure 5). 

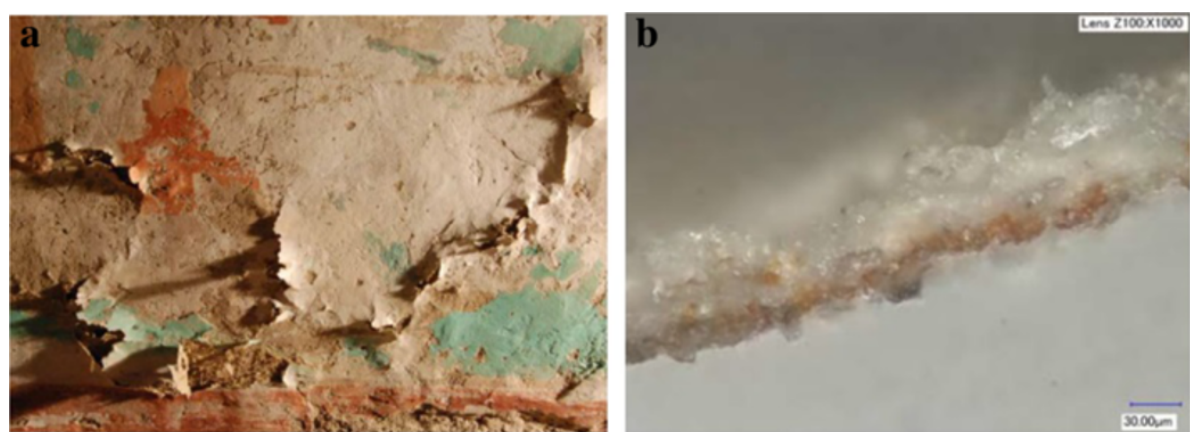

Figure 4 Disruption on the west wall. (a) picture of disruption, (b) microscopic picture of disruption in $1000 \times$.

Flaking caused by the reinforcement material is quite different. The grounding layer or paint layer is warped in a sheet-like form with relatively thick encrustation. This flaking, with a wide range and large amount, is severe once it appears. The main reason is that the reinforcement material can form a thick layer of encrustation, which is different from the plaster layer in the way they react to humidity and temperature changes. The contraction and expansion deformation between layers leads to the crack and warp of the reinforcement layer. To verify this, a few model samples of Dunhuang mural were prepared in the lab. PVA, acrylic emulsion, silicone acrylic emulsion, and paraloid B72 were used as the reinforcement materials to consolidate the samples which were tested under dry-wet cycles. Obvious flaking was observed on the samples after a few cycles, which was quite similar to the disease in Mogao Grottoes. The experimental results indicated that the degree of flaking was obviously related to the concentrations of the reinforcement materials, and their types as well. Under the same concentration, the degree of flaking varied among different conservation materials: samples reinforced by PVA, acrylic, silicone acrylic were more resistant to the dry-wet cycles, while samples protected by paraloid B72 were more likely to flake (Figure 6). The practice of repairing murals by Dunhuang Academy also showed that PVA was quite effective in the repair of flaking.

The renewed flaking after repair mostly occurred in the caves in which gelatin solution or the hybrid emulsion was used. The appropriate conservation material should not be easy to form a crust layer and its concentration is also important. In this respect, PVA with low concentration shows relatively good effect in repairing flaking.

\section{Detachment}

Detachment is the phenomenon that part of plaster layer is separated from the rock substrate, but the peripheral of the part is still connected with the substrate. Detachment was found in the area under $2 \mathrm{~m}$ above the ground of many caves, covering the area of $6.55 \mathrm{~m}^{2}$, about $1.6 \%$ of the total disease area (Table 2). Most of them are severe, and the murals might fall at any time.

There are mainly four reasons which can cause detachment. First, the imperfection in the production of murals may lead to the separation of plaster from the rock. Second, salt crystallization can cause the plaster layer being loose and tender, then separate from the rock. Third, the intensive and frequent changes of temperature and humidity may reduce the adhesion strength between plaster and rock. Finally, the improper
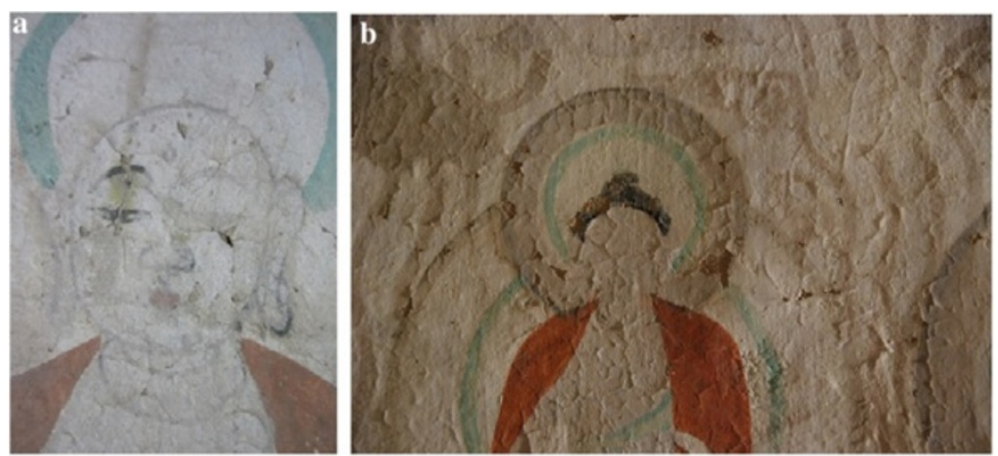

Figure 5 Pictures of flaking. (a) flaking on the center column in the 44th cave. (b) flaking after using gelatin solution to repair. 

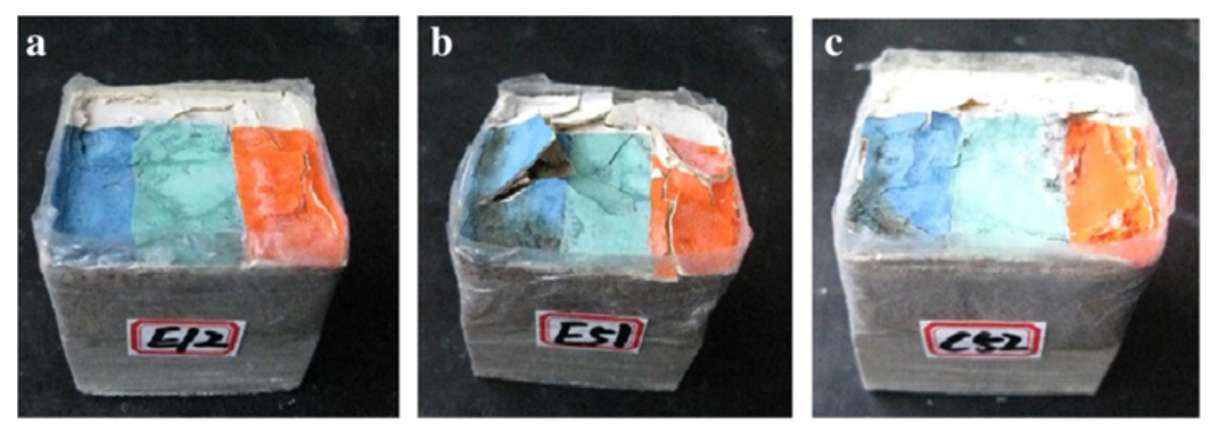

Figure 6 Pictures of model samples using different reinforcement materials under dry-wet cycles. (a) sample repaired with 1\% PVA. (b) sample repaired with $5 \%$ B72. (c) sample repaired with $5 \%$ acrylic emulsion.

conservation materials and treatments can cause the damage of murals.

Salt crystallization is one of the most important reasons that cause detachment. The porosity and capillary water migration in the plaster layer and rock are not exactly the same. Soluble salts can migrate between the plaster layer and the support, and they are likely to accumulate near the interface. Continuous solvation-crystallization process makes the plaster layer, especially the interface region between the plaster and the support friable, which damages the adhesion between them and thus causes detachment. Salt crystallization always occurs in the wider regions, resulting in a large area of detachment, with the murals hanging on the wall like a curtain, easy to fall once the adhesion is lost. Besides, when repairing the detachments, adhesion materials are always used for grouting the crevice between the plaster and the rock. Although the grouting materials can strengthen the murals, they have drawback -- changing the migration of the capillary water. This drawback becomes more severe when the grouting materials' water vapor permeability is not good. It will result in an obvious obstacle interface and will accelerate the accumulation of soluble salts, finally leading to new detachment or disruption. After numerous trials, a systematic desalination method has been proposed by conservators in Dunhuang Academy [37]. At present, desalination can be conducted simultaneously with grouting, which has been proved to be highly effective in the repair of detachment [38].

In the 1980s, cement and lime were used to repair the detachment and paint loss of murals. In this survey it is found that detachment was very easy to appear in the place where cement and lime were used. For example, cement was used to repair the plaster loss on the bottom of west wall in the 29th cave and had certain protective effect since then. But severe detachment appeared in the protected area (Figure 7a). According to the picture of infrared thermography (Figure 7b), detachment not only appeared in the part repaired by cement, but also in the position joint with the repaired part. The physical properties of cement and lime are quite different the plaster layer. Each material reacts differently to aging, temperature and humidity change. The differences in the properties can block the movement of water and salts, resulting in the detachment finally. The harm of using cement and lime to repair murals has gradually been recognized and they are avoided in the conservation now.

The investigation showed that the movement of water and salt is the main cause of detachment, and improper grouting and conservation materials also can lead to the generation and development of detachment. Therefore, environment control, using more appropriate conservation materials and techniques and replacing those

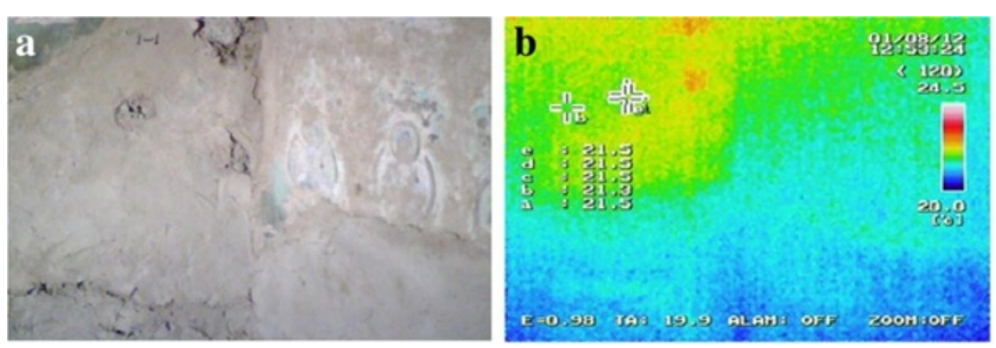

Figure 7 Pictures of detachment. (a) detachment on the bottom of west wall in the 29th cave, (b) the infrared thermography picture of detachment. 


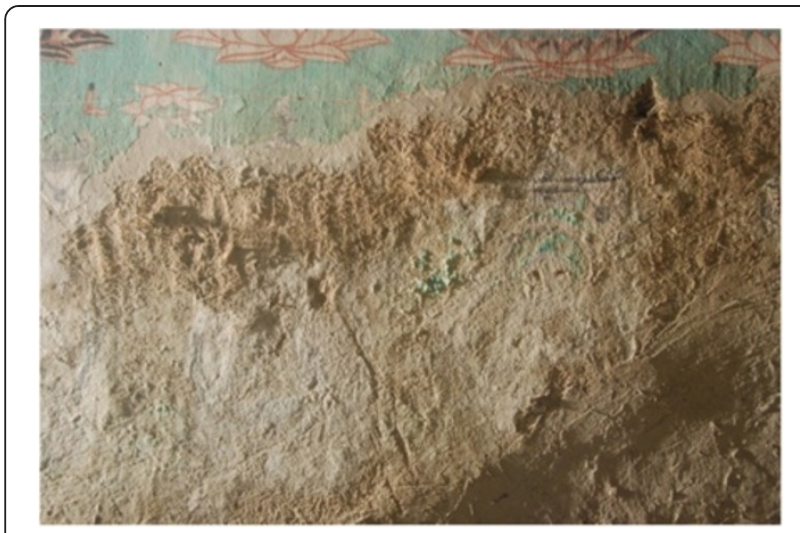

Figure 8 The paint loss on the north wall of the 29th cave.

materials used in the early time are the effective measures for the treatment of detachment.

\section{Paint loss}

The paint loss refers to the falling paint layer from plaster or grounding layer [39]. According to this investigation, the paint loss reached up a total area of $6.43 \mathrm{~m}^{2}$, accounting for $15.5 \%$ of the total diseases, most of which were severe.

Paint loss can be caused by the deterioration of the adhesion materials and other diseases. When the adhesion materials deteriorate, the pigments can't stick to each other or the plaster layer, then the paint layer drop gradually, especially on the murals with thinner pigment layer or less adhesion. In this investigation it is found that paint loss caused by the deteriorated adhesion material isn't too much.

Most of paint loss usually occurred in the place where there were severe disruptions. The severe paint loss is characterized by large areas of paint layer dropping off near the disruption areas. Large areas of paint layer were missing because the severe disruption made the paint layer lose adhesion to the plaster layer.

Flaking usually leads to crack, warp and finally drop of the paint layer. Paint losses caused by flaking are common, and most of them are mild or slight. Sometimes, the severe paint loss was caused by the joint influence of disruption and flaking. Figure 8 shows that the severe paint loss is around the area of disruption, and flaking is obvious in the middle of that area. In general, flaking and disruption can lead to severe paint loss eventually. Once the paint layer falls, it's difficult to restore. So the best way to prevent the murals from paint loss is dealing with disruption and flaking in time.

\section{Conclusions}

According to the on-site investigation of the renewed diseases of the murals which were repaired in Mogao
Grottoes, we found that disruption is the most common renewed disease, followed by flaking, detachment, and paint loss. The area of these four diseases is $38.43 \mathrm{~m}^{2}$, reaching up to more than $90 \%$ in the total disease area. Most of them are severely deteriorated and threaten the preservation of the murals.

The movement of water and salts affected most of the renewed diseases in the repaired caves. The migration and accumulation of soluble salts can severely damage the murals, and it is difficult to eradicate. Three types of conservation materials have been used to repair the murals, including PVA, the hybrid emulsion of acrylic and silicone acrylic, and gelatin solution, which played important roles in the conservation of murals. However, in the region where water and salts move frequently, these materials cannot prevent from the damage of disruption, and the reinforcement ability of the conservation materials is far less than the destructive force of the environment.

If the cave's environmental conditions are basically the same, the possibility of the renewed flaking is lower when the murals were repaired with PVA, while the possibility of paint loss is lower when the murals were repaired with hybrid emulsion of acrylic and silicone acrylic. The hybrid emulsion also performs better to repair disruption and detachment. However, it is still difficult to fully evaluate these conservation materials only based on the current investigation, since the experimental results of scientific concern are not enough. Further research on their deterioration mechanism is needed.

The conservation materials used in the early time, such as cement and lime, are not appropriate and can even damage the murals. The questions of how to remove these materials safely and thoroughly and what kind of material can replace them are very important and will be answered by further studies.

\section{Consent}

Written informed consent was obtained from the patient for the publication of this report and any accompanying images.

\section{Competing interests}

The authors declare that they have no competing interests.

\section{Authors' contributions}

$J \mathrm{~L}, \mathrm{HZ}, \mathrm{XH}, \mathrm{SH}, \mathrm{MS}, \mathrm{YM}, \mathrm{SF}$ and BZ carried out the on-site investigation. ZF and $\mathrm{HZ}$ from Dunhuang Academy provided support and guidance for this investigation. $J$ analyzed the results. $J \mathrm{~L}$ and $\mathrm{HZ}$ drafted the manuscript. All authors read and approved the final manuscript.

\section{Acknowledgement}

The National Basic Research Program of China (Grant Number 2012CB720902), National Science and Technology Support Program of China (Grant Number 2012BAK14B05) and the Historic Preservation Special Foundation of Zhejiang Province (Grant Number 2010-264) are greatly acknowledged for their financial support. The authors also express their gratitude to the staffs of Dunhuang Academy for their support during the survey. 


\section{Author details}

${ }^{1}$ Department of Cultural Heritage and Museology, Zhejiang University, Hangzhou 310028, China. ²Department of Chemistry, Laboratory of Cultural Relics Conservation Materials, Zhejiang University, Hangzhou 310027, China. ${ }^{3}$ Dunhuang Academy, Dunhuang 736200, China. ${ }^{4}$ National Research Center for Conservation of Ancient Wall Paintings, Dunhuang 736200, China.

Received: 13 March 2013 Accepted: 25 September 2013

Published: 1 October 2013

\section{References}

1. Fan JS: The preservation, maintenance and prospected of Mogao Grottoes. In Dunhuang research corpus - grottoes protection. Edited by Dunhuang Academy. Lanzhou: Gansu National Press; 1993:4-12.

2. Shi YC, Zhang J: The Dunhuang Caves'main diseases and precautions against them. Northwest Seismological J 1997, 2:81-87.

3. Li ZX: The protection present situation and task of Dunhuang Grottoes. Dunhuang Res 2000, 1:10-23.

4. Chen GQ, Su BM, Zhao LY, Yu ZR, Li ZX, Agnew N: The simulation test of mural plaster disruption of cave 85 at Mogao Grottoes. Dunhuang Res 2005, 4:62-66.

5. Kang WH: Study on Preparation of Desalination Materials for Dunhuang Murals. Lanzhou: Master Thesis. Lanzhou University, Department of Chemistry; 2006.

6. García-Diegoa F, Zarzo M: Microclimate monitoring by multivariate statistical control: the renaissance frescoes of the Cathedral of Valencia (Spain). J Cult Herit 2010, 11:339-344.

7. Zarzo M, Fernández-Navajas A, García-Diegoa F: Long-term monitoring of fresco paintings in the cathedral of Valencia (Spain) through humidity and temperature sensors in various locations for preventive conservation. Sensors 2011, 11:8685-8710.

8. Merello P, García-Diegoa F, Zarzo M: Microclimate monitoring of Ariadne's house (Pompeii, Italy) for preventive conservation of fresco paintings. Chem Centr J 2012, 6:145

9. Visco G, Plattner SH, Fortini P, Giovanni SD, Sammartino MP: Microclimate monitoring in the Carcer Tullianum:temporal and spatial correlation and gradients evidenced by multivariate analysis; first campaign. Chem Cent J 2012, 6(suppl 2):511.

10. Visco G, Plattner SH, Fortini P, Giovanni SD, Sammartino MP: Second campaign of microclimate monitoring in the carcer tullianum: temporal and spatial correlation and gradients evidenced by multivariate analysis. Chem Cent J 2012, 6:104

11. Xu SQ: The investigation report of Mogao Grottoes 98th cave. Dunhuang Res 2005, 5:75-77.

12. Zhang Y: Existing Condition Investigation and Research on Main Deterioration Mechanism of Cave 87 at the Mogao Grottoes. Lanzhou: Master Thesis. Lanzhou University, Department of Civil Engineering; 2011.

13. Wang XW, Chai BL, Sun SL: The thinking about investigation record method of Mogao Grottoes murals. Dunhuang Res 2007, 5:103-106.

14. Li YH: Technology of taking off and transferring the whole multi-layered mural. Dunhuang Res 1988, 3:63-66.

15. Huang LX, Gao PF, Xiao GQ, Wang XD, Guo QL: Experiment of probing thickness of the Mogao Grottoes Frescoes by the ground penetrating radar. J Liaoning Technical University (Natural Science Edition) 2001, 4:457-459.

16. Fan JS: The conservation and management of The Mogao Grottoes. Dunhuang Res 2000, 1:1-4

17. Li ZX: Sixty years on the conservation of The Dunhuang Grottoes. Dunhuang Res 2004, 3:10-26.

18. Dunhuang Academy China: Summary of Dunhuang Grotto preservation. Art Design 2008, 6:22-27

19. Li ZX, Nishiura T: Choice test of mural reinforcement material. Dunhuang Res 1988, 3:60-63.

20. Sun RJ: Several problems of murals protection at Mogao Grottoes. Dunhuang Res 1985, 2:169-173.

21. Li YH: Trial for repairing Dunhuang wall painting. Dunhuang Res 1985 , 2:174-184

22. Fan ZX: The mural restoration report of the disease in Mogao Grottoes 94th cave. Dunhuang Res 2000, 1:136-138.

23. Duan $X Y$, Sun $\mathrm{HC}$ : A report on the restoration of the alkalized murals in cave 108 at Mogao Grottoes. Dunhuang Res 1990, 3:92-94.
24. Fan ZX, Chen GQ, Su BM, Li YF, Qiao H, Tang W: The testing study for repairing the disruption wall paintings in Cave 98 at Mogao Grottoes. Dunhuang Res 2009, 6:4-7.

25. Fan ZX, Rickerby S, Shekede L, Qiao H, Tang W: The technique measurement for repairing the mural-paintings in Cave 85 at Mogao Grottoes. Dunhuang Res 2008, 6:19-22.

26. The People's Republic of China State Administration of Culture Heritage: Specification for Condition Survey of Ancient Murals. Beijing: Cultural Relic Press; 2007.

27. Xu SQ, Wang XD, Sun HC, Li WT, Zhen J: The investigation and assessment of mural diseases in cave 85 at Mogao Grottoes. Dunhuang Res 2000, 1:174-180.

28. Wang JF, Yan GS, Yang SL: Distribution of soluble salts in the cliff strata of the Mogao Grottoes. Hydrogeol Eng Geol 2010, 6:116-120.

29. Guo H, Li ZX, Qiu YX, Tang JR, Yang FJ: Resarch on efflorescence of wall paintings in the Mogao Grottoes of Dunhuang (I). Dunhuang Res 1998, 3:153-163.

30. Guo H, Li ZX, Qiu YX, Tang JY, Yang FJ: Resarch on efflorescence of wall paintings in the Mogao Grottoes of Dunhuang (II). Dunhuang Res 1998, 4:159-161

31. Guo H, Li ZX, Qiu YX, Tang JY, Yang FJ: Resarch on efflorescence of wall paintings in the Mogao Grottoes of Dunhuang (III). Dunhuang Res 1999, 3:153-164.

32. Su BM, Chen GQ, Fan ZX, Ma JT, Kang HW, Li R: The application research of a new synthesized desalination material on the treatment of salting damage wall paintings in Mogao Grottoes. Relics Museol 2009, 6:175-183.

33. Wang XD, Zhang MQ, Zhang HY, Zeng ZZ, Yao Z, Zhou ZH: Engineering properties of surrounding rocks of Mogao Grottoes at Dunhuang. J Rock Mechan Eng 2000, 6:756-761.

34. Chen GQ, Yu ZR: Test for blister and soluble salt in powdering and the layer of plaster for the wall-paintings in Cave 351 at Mogao Grottoes. Relics Museol 2009, 6:39-45.

35. Guo QL, Wang XD, Xue P, Zhang GB, Fan ZX, Hou WF, Zhang ZM: Research on spatial distribution and relations of salinity and moisture content inside rock mass of low-layer caves in Dunhuang Mogao Grottoes. Chin J Rock Mech Eng 2009, 28:3769-3775.

36. Duan XY, Fu P, Fu YX, Xu SQ: The restoration of disruption mural hanging in 16th cave at Mogao Grottoes. Dunhuang Res 2005, 4:30-34.

37. Ma ZF, Aoki S, Quan ZH: Screening the material for repairing murals plaster at Mogao Grottoes in Dunhuang. Dunhuang Res 2007, 5:22-27.

38. The People's Republic of China State Administration of Culture Heritage: Specification on desalination technology of ancient murals. Beijing: Cultura Relic Press; 2010

39. The People's Republic of China State Administration of Culture Heritage: Specification on damage glossary and legend of ancient murals. Beijing: Cultural Relic Press; 2008.

doi:10.1186/2050-7445-1-31

Cite this article as: Li et al.: Investigation of the renewed diseases on murals at Mogao Grottoes. Heritage Science 2013 1:31.

\section{Publish with ChemistryCentral and every scientist can read your work free of charge \\ "Open access provides opportunities to our colleagues in other parts of the globe, by allowing anyone to view the content free of charge." W. Jeffery Hurst, The Hershey Company.}

- available free of charge to the entire scientific community

- peer reviewed and published immediately upon acceptance

- cited in PubMed and archived on PubMed Central

- yours - you keep the copyright

Submit your manuscript here:

http://www.chemistrycentral.com/manuscript/<smiles>c1ccccc1</smiles> 